\title{
A mente incorporada no controle de processo contínuo: ação, cognição e comunicação na atividade de trabalho
}

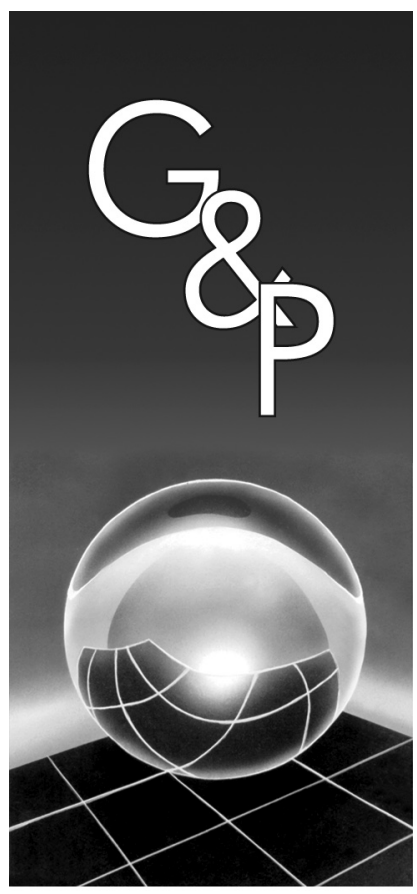

Gilbert Cardoso Bouyer

\begin{abstract}
Resumo
O principal objetivo deste artigo é analisar, em detalhe, a cognição como ação incorporada no controle de processo contínuo. O método de pesquisa é a análise ergonômica do trabalho. Os resultados mostram que os operadores não representam um mundo externo, mas pensam e agem de forma interdependente. O ponto chave neste texto é que, sem nada como uma representação interna, trabalhadores (operadores) se engajam na atividade de trabalho numa coordenação sensório-motora em resposta para mudanças ambientais. Não há ruptura na experiência entre perceber, sentir e pensar. Esta pesquisa busca responder como os processos social e cultural são demandados para desenvolver esquemas-imagem e esquemas-incorporados, os quais podem realizar pensamento abstrato usando suas capacidades de percepção e resposta motora. Este trabalho postula que as expressões lingüísticas e os processos cognitivos de nível superior evidenciam padrões dinâmicos de experiência corporal recorrente denominados esquemas-imagem. Este trabalho afirma que estes padrões podem ser estendidos a estruturas de experiências não-tácita, não-física e não-visual.
\end{abstract}

Palavras-chave: Ergonomia. Atividade. Controle de processo. Mente incorporada.

\section{Introdução}

Nos últimos anos, a ergonomia tem se voltado para o estudo da atividade de trabalho de controle de processo nas indústrias de processo contínuo (IPC). Nesta atividade, destaca-se a sua natureza essencialmente cognitiva. Controlar um processo contínuo, por intermédio de um sistema automatizado, implica colocar os saberes incorporados e a cognição incorporada em funcionamento para manter o processo de produção dentro dos parâmetros predeterminados de normalidade. Este trabalho postula a tese de que as ações de abstração no controle de processo, as quais envolvem as funções cognitivas superiores (VYGOTSKY, 1996), dependem, para sua efetivação, da incorporação do agente no contexto de cada situação da área de produção.

A cognição do operador funciona apoiada sobre sua ação situada (LAVE, 1996) num dado contexto, em que as funções sensório-motoras e a ação perceptivamente orientada (como no caso da utilização de indicadores indiretos do processo) são demandadas para garantir a eficiência do processo contínuo de produção.

Este estudo aplicou os métodos e técnicas da análise ergonômica do trabalho (AET), juntamente com outras técnicas de análise das experiências e verbalizações dos operadores, para avaliar a natureza desta ação incorporada no controle de IPC.

Assim, esta pesquisa constatou que, em sua atividade, os operadores eficientes agem conforme a noção de "ação incorporada" ou embodied action i.e. embodied mind (ROHRER, 2005, 2006; PESCHL, 2000; JOHNSON; ROHRER, 2006). Ou seja, ao contrário do ponto de vista mais difundido (objetivista; representacionista), segundo o qual a atividade de um operador de controle de IPC, diante de uma tela de computador, é principalmente abstrata, as análises realizadas com 32 operadores, constataram que a atividade de abstração ou atividade cognitiva de controle da IPC, por intermédio do sistema automatizado está, de fato, fundamentada na experiência sensório-motora, corporal ou "incorporada" dos operadores que vivenciaram a história do processo produtivo (geralmente como supervisores de área ou auxiliares de produção). Além da história de incorporação, faz-se necessário, no momento presente da ação, que o operador se mantenha incorporado ao contexto das situações, mediante a percepção de indicadores indiretos (não 
fornecidos pelo sistema), comunicação com os demais atores da produção, situados na área, e forte integração ao contexto de situações, ocorrências e eventos da área de produção. É esta incorporação, envolvendo o corpo (funções sensoriais, ação perceptivamente orientada, funções sensório-motoras) que permite a inteligência do controle de processo funcionar a contento.

Essa experiência de incorporação ao processo produtivo possibilita, também, a gênese instrumental (RABARDEL, 2005; PASTRÉ, 2005) nos operadores, ou seja, a aquisição de esquemas incorporados do tipo image-schemata (ROHRER, 2005), os quais consistem em padrões recorrentes de ativação do córtex sensóriomotor que se expandem, como metáforas (LAKOFF, 1987; JOHNSON, 1987; JACKENDOFF, 1987), até formarem a compreensão das experiências e situações por parte dos operadores, bem como a efetivação das funções cognitivas superiores (linguagem, raciocínio hipotético, dedução, indução, previsão/antecipação dos estados futuros do processo de produção).

Os métodos de pesquisa para identificar os imageschemata priorizam a avaliação da linguagem dos operadores, no seu contexto de atuação. É na linguagem que se manifestam as metáforas incorporadas, as quais permitem a essa cognição incorporada funcionar de modo a garantir a eficiência no controle do processo. Foi necessário aprofundar e reformular os métodos de análise das verbalizações descritos por Wisner (1987) e Guérin et al. (2002), e também ampliar as etapas de autoconfrontação em AET, de modo a identificar os padrões recorrentes de natureza sensório-motora que sustentam as ações mais abstratas.

Segundo as ciências cognitivas contemporâneas (LAKOFF, 1987; LAKOFF; JOHNSON, 1980) esses padrões recorrentes ou image-schemata são de ordem cortical sensório-motora, originados na experiência dos operadores com o mundo físico (corporal). Eles são de natureza não-proposicional e antecedem a atividade cognitiva superior (verbal, intencional).

Os resultados encontrados neste trabalho sintonizam-se com estes postulados das ciências cognitivas atuais, tecidos sobre a relação entre os image-schemata e a história de incorporação dos agentes (ROHRER, 2005): os operadores mais eficientes, dentre os 32 estudados, são aqueles que se mantêm incessantemente incorporados ao contexto da área de produção. Eles apresentam um farto repertório de image-schemata em sua ação e, ao mesmo tempo, são os operadores que iniciaram sua história na área de produção, em contato direto com os equipamentos, matérias-primas, insumos e outros atores da planta.

Quais diferenças esta pesquisa detectou? Os agentes que possuem uma história de incorporação à planta, $\mathrm{e}$ que se mantêm incorporados a ela, são mais eficientes no controle do processo, segundo os critérios de eficiência definidos por Bainbridge (1987). Essa incorporação funciona como se o corpo do operador, seus músculos, seus nervos e estruturas aferentes e sensoriais se estendessem por toda a planta, por meio de recursos diferenciados de comunicação extra-sala de controle, os quais, de fato, tornam o operador como um corpo estendido e situado sobre a refinaria, sobre a fábrica de cimento, sobre a usina - corpo que reconstrói e reorganiza os sinais do processo, a todo o momento, e os reformula numa função de reenquadramento - ao que Merleau-Ponty (2006) dá o nome de "forma - função de enformação" (ou seja, reenquadramento dos estímulos conforme a estrutura e organização interna do agente, formadas pelos esquemas incorporados para a ação e pelos image-schemata). Vem desta história de incorporação (passado) e da incorporação no instante atual (presente), em seus elementos concretos, a ação incorporada e eficiente no controle da IPC. Algo que aparenta, ao olhar do observador, tratar-se puramente de raciocínios, imagens e estratégias mentais abstratas (desincorporadas) para a ação eficaz sobre o processo. Trata-se, na realidade, de uma "representação sem representação" (PESCHL, 2000), devido ao seu caráter situado e incorporado.

\section{Problema de pesquisa}

Por que os operadores que, antes de se tornarem operadores de controle de processo contínuo, eram trabalhadores da área de produção, trabalhando em contato com as matérias-primas, com a realidade material e concreta da produção contínua (boca do forno, operador de ponte, dangueiro e lingoteiro na siderurgia, supervisor de área, etc.), e hoje são operadores de sistemas automatizados de controle de processo contínuo, conseguem obter um desempenho cognitivo superior ao verificado com os operadores que não possuem esta mesma história de incorporação ao processo produtivo?

Para compreender o problema estudado, foi preciso abandonar a pressuposição de que a cognição humana funciona por representação mental (não-situada, desincorporada) e segundo um suposto modelo de processamento de informações vindas do mundo exterior ao agente. Esse equívoco teórico tem levado à materialização de sistemas e dispositivos técnicos que não respeitam as condições reais de funcionamento da cognição humana em atividade de trabalho, gerando sobrecargas, danos materiais e de saúde.

Por que o operador necessita manter contato físico, corporal, sensório-motor (comunicacional, sensorial, visual, etc.) com a área do processo de produção, ou seja, manter-se continuamente incorporado a ela? A idéia de um mundo exterior a ser representado pelo agente (operador) não coaduna com suas condições de atuação 
- e viola a noção de "mente incorporada" das ciências cognitivas contemporâneas (PESCHL, 2000; ROHRER, 2005, 2006; BERTHOZ, 1997). O idealismo da representação mental é nocivo à saúde e à produtividade do trabalhador na medida em que ignora a influência do corpo e da materialidade psicofísica dos agentes na sua ação. Ao invés de "representar", o agente está, de fato, a "atuar" (atuação, atuacionismo) por meio de esquemas corporificados/incorporados ou embodied-schemata; image-schemata (JOHNSON \& ROHRER, 2006; ROHRER, 2005, 2006).

\subsection{Embodiment: ação incorporada e eficiência no controle do processo contínuo}

$\mathrm{Na}$ capacidade de compreender um fato ou evento da produção, conectando experiências concretas com compreensão e raciocínio mais abstratos, há padrões que organizam e dão sentido às ações, percepções e concepções: os schemata. Eles são padrões recorrentes, formatados pela experiência incorporada; dotados de certa regularidade, ordenando a atividade cognitiva. Esses padrões emergem dotados de significação como estruturas arraigadas no nível dos movimentos incorporados situados no espaço físico, manipulação de objetos e instrumentos, interações perceptivas e ação perceptivamente orientada.

Os image schemata possuem um caráter dinâmico. São estruturas de organização da experiência e compreensão, estruturas contínuas de organização da atividade. São estruturas de uma atividade (engendradas pelas interfaces entre os mundos biológico, social e psíquico) que organizam a experiência de modo a torná-la dotada de significado para o agente.

Elas (as estruturas incorporadas) indicam que um operador constrói a experiência em si, confere-lhe significado, não funcionando, portanto, como um mero receptáculo vazio de informações (entradas), elaboração de representações e emissão de saídas. Os schemata são flexíveis a tal ponto que podem ser aplicados a um variado número de situações, específicas, em vários contextos. Embora flexíveis e relativamente maleáveis, podendo ser conformados a diferentes situações, eles mantêm uma estrutura subjacente que manifesta seu caráter recorrente e incorporado nessas situações distintas de trabalho. Eis, aqui, um ponto fundamental para a Ergonomia em sua busca por compreender a fundo as situações de trabalho e as variáveis de ação e/ou variáveis de ajuste.

Em suma, não existem percepções permanentemente fixas numa realidade objetiva e independente dos agentes (conforme sugere o objetivismo). Elas adquirem forma e inteligibilidade ao se instalarem num dado contexto de significação no qual operam os esquemas incorporados da ação operatória. Para muito além de um ponto de vista que crê na compreensão e significação baseadas na imposição de conceitos, proposições e planos, há, nesses, de fato, uma "ação cognitiva situada", na qual os image schemata, com suas estruturas, organizam e dão forma à experiência vivenciada pelo agente.

Por exemplo, o sentido do "dentro-fora" de compreensão, na ação, envolve a capacidade física de orientação no espaço, atrelada às capacidades mais abstratas de caráter não-espacial. O mesmo ocorre com os elementos do tipo "acima-abaixo", "próximo-longe", "direito-esquerdo", "frente-trás", etc. (SANTIBÁÑEZ, 2002). O que acontece, de fato, é que a capacidade de abstração e compreensão da realidade, a forma como o agente atribui significação ao mundo do trabalho, está intimamente associada a um sentido mais mundano, mais corporal e operacional. Este sentido envolve complexas interações com o ambiente no qual os agentes vivenciam (e vivenciaram) o mundo concreto, suas leis físicas sobre o corpo, pelas quais desenvolvem padrões recorrentes ligados à sensório-motricidade e à percepção de índices informais do processo.

Complexos processos de significação e compreensão, necessários para a eficácia na produção, envolvem esses image-schemata originados nos contatos mais elementares com o mundo do trabalho. Neste caso, podem ser observados os complexos processos de percepção de características físicas, químicas ou físico-químicas utilizados para a garantia da qualidade num processo produtivo ( $c f$. casos das indústrias siderúrgica, petroquímica e de cimento).

O senso de orientação na atividade abstrata (em que direção e sentido alterar as variáveis do processo, e com qual finalidade) está intimamente associado à experiência de orientação corporal, sensório-motora e perceptiva do operador. Ou seja, sua atividade mais abstrata, que envolve julgamento e tomada de decisão, está bem intimamente ligada à sua experiência corporal (percepção dos indícios materiais do processo, externos à sala de controle; comunicação com a área; integração-incorporação ao contexto exterior ao ambiente de trabalho).

Em outras palavras, operador de processo contínuo (mais eficiente...) precisa muitas vezes levantar-se da poltrona e ir até a janela observar características visuais do processo de fabricação ou então contar com a movimentação do pessoal da área: trata-se, respectivamente, das componentes perceptiva e sensório-motora da ação.

Nestes casos, verificou-se que o corpo funciona como reservatório do pensamento utilizado na atividade de trabalho; o sentido da ação apóia-se nos movimentos do corpo, manipulação de instrumentos e artefatos, experiências físicas concretas, percepção de indicadores indiretos, comunicação extra-sala de controle. Daí, um esquema emerge inicialmente nessas experiências e intercâmbios incorporados do operador-agente, em suas percepções e em seus movimentos, permitindo a compreensão dos 
estados do processo e a orientação da ação rumo a uma finalidade.

No vocabulário dos operadores, transbordam figuras de linguagem que demonstram as extensões metafóricas dos esquemas incorporados. Esquemas de movimento, de noções como "dentro-fora"; "acima-abaixo"; "pertolonge"; etc., enquanto esquemas de orientação espacial surgem, metaforicamente (LEMMENS, 2004; LAKOFF; JOHNSON, 1980), projetados no domínio cognitivo de atuação, sustentando os processos abstratos de escolha, julgamento, modificações nas variáveis do processo contínuo e antecipação dos estados futuros do processo.

O conteúdo dos esquemas incorporados permeia as múltiplas modalidades da ação operatória, incluindo-se desde as componentes atreladas à atividade comunicacional, aos intercâmbios intersubjetivos, às conversações e às habilidades de intercompreensão verificadas nos agentes situados num mesmo domínio de atuação.

$\mathrm{O}$ que se manifesta na linguagem, na intercompreensão, nas comunicações de fábrica, envolve um caráter pré-conceitual, não-verbal, situado no domínio incorporado (embodiment), intangível e não-simbolizado, anteriormente citado. Esse ponto de vista não é algo dado na dimensão de conceitos e proposições. Ele é resultado dos embodied-schemata (espaciais, temporais, metafóricos). Uma estrutura está ativa, mas não está no plano da consciência do agente (não representada e não representável). Não está registrada em proposições explícitas (representações) que correspondam fielmente ao pensamento verbal reflexivo. Resulta, ao invés disso, da recorrência de padrões sensório-motores que emergem nas experiências com eventos do mundo físico.

Um image-schema exerce uma função importante e complexa enquanto estrutura de significação na experiência de compreender, interpretar e atribuir significado aos estados do processo (variáveis, curvas, tendências de variação, oscilações). A compreensão desses aspectos do processo, por parte do operador-agente, depende dessas estruturas incorporadas e da incorporação (embodiment), responsáveis por organizar a experiência, conectar diferentes domínios de vivências na atividade de trabalho e conferir coerência e unidade aos processos de compreensão do processo produtivo.

\section{Métodos de pesquisa}

Destaca-se, neste trabalho, o ponto de vista de que um substancial desenvolvimento epistemológico (construção de novos conhecimentos) e ontológico (compreensão da atividade concreta, na qual age o ser que trabalha) foi concedido à ergonomia pela metodologia da AET, em seu aprofundamento (empírico) nas verbalizações dos operadores, o que se torna intensamente fértil no procedimento de "autoconfrontação". Com os métodos de entrevista e de análise das verbalizações fornecidos pela AET, no presente estudo, foi possível objetivar dados, fatos, saberes e conhecimentos dantes reclusos na parte não visível da ação dos trabalhadores.

No presente trabalho, foi necessário explorar mais ainda o discurso dos operadores, no nível de suas experiências vividas em atividade de trabalho. As experiências vividas no trabalho são aquelas que não descartam as componentes mais subjetivas da ação, como os aspectos psíquicos, as sensações e as percepções. Essas componentes interagem e afetam as componentes cognitivas e, conseqüentemente, os resultados da ação (desempenho, eficiência). Em suma, os métodos e técnicas de verbalizações da AET foram readaptados, tornando-se uma espécie de análise das verbalizações fornecidas sobre o que era vivido em situações nas quais os próprios atores (operadores, trabalhadores) julgavam ter marcado a sua história no controle do processo contínuo.

De acordo com a AET (WISNER, 1987, 1994), o discurso dos trabalhadores a respeito da atividade de trabalho deve ser mediado pelos traços objetivos da própria atividade. Sendo uma grande parte da atividade regulada de forma subconsciente, unicamente a observação exterior e sistemática das ações visíveis não possibilita um acesso à consciência dos trabalhadores e às suas estratégias mentais. Assim, neste trabalho de pesquisa, a AET veio a contribuir de modo a fornecer um contorno mais nítido e objetivo para as verbalizações dos operadores, aprofundadas na investigação do mundo vivido no trabalho ou le monde commun (PASTRÉ, 2005) pelos métodos também familiares à psicossociologia do trabalho de Enriquez (1995): ampliação do espaço para emergência de um discurso mais livre e menos estruturado.

Para adentrar na vivência cognitiva dos operadores, foram empregadas também (além da AET) essas técnicas da psicossociologia (ENRIQUEZ, 1995), as quais permitem dar espaço amplo ao discurso dos trabalhadores. Estas foram empregadas nas sessões realizadas com pequenos grupos de dois ou três operadores, simultaneamente entrevistados.

O discurso, até certo grau livre, mediado pelo entrevistador e com condições de contorno dadas tanto pelas situações do trabalho quanto pelas vivências no trabalho (nos mesmos moldes das entrevistas de natureza psicossociológica), muitas vezes foi regredindo a momentos pretéritos, às vezes, longinquamente situados na história de cada operador, em sua atividade. Pode-se, então, dizer que, por permitir elucidar melhor o objeto investigado, via estes resgates de situações vivenciadas no tempo pretérito da trajetória histórica (na atividade de trabalho) de cada trabalhador, o método da história de vida (BECKER, 1997) não se desprendeu, e não se isolou do discurso ora desencadeado pelas entrevistas situadas no domínio da 
psicossociologia e da AET. Significa, portanto, que numa primeira fase, discurso psicossociológico e discurso de história de vida caminharam integrados um ao outro, em consonância com as verbalizações incitadas pelos métodos e técnicas da AET.

Nos métodos da AET, procurou-se manter o verbo no presente e remeter o sujeito ao seu próprio comportamento, de acordo com aquilo que fora observado. Questões do tipo "o que você está fazendo na..."; "como você soube que..."; "quando é que você auxilia... o que fez você decidir por esta intervenção..." etc., foram largamente empregadas, conforme métodos propostos por Wisner (1987, 1994). O contexto imperou nesta fase da pesquisa. A objetividade, a reconstituição minuciosa das situações de trabalho, as observações sistemáticas juntaram-se e buscaram conduzir as falas, o discurso, culminando em momentos graves de confrontação daquilo que se dizia com aquilo que se observava e que se tinha, concretamente, numa situação real contextualizada.

\subsection{Contextualização dos métodos de pesquisa e do campo empírico: procedimentos de pesquisa}

A constituição, histórica, do sujeito capaz e eficiente, incorporado e situado no seu contexto de ação - eis o objeto de estudo da presente pesquisa. O material empírico essencial deste trabalho de pesquisa é constituído pelo discurso dos operadores. As falas ou verbalizações foram o substrato primordial para as análises. Ainda que aparente se tratar de frases ou enunciados soltos, ou aparentemente isolados de um contexto, eles guardam íntima relação com as situações específicas de trabalho e com os contextos da atividade de trabalho estudados. Não foi apenas o contexto, não foram apenas as condições de contorno da situação e não foram somente as variáveis do processo os objetos de análise desta pesquisa. O objeto de análise, neste estudo, foi, fundamental e essencialmente, a fala do trabalhador.

Na fala, por meio da fala, todas as hipóteses de pesquisa ora formuladas puderam ser investigadas. Ainda que as situações carreguem consigo os aspectos de um ambiente de engenharia, ou resquícios das técnicas e processos de produção, não foram os aspectos técnicos do processo e da engenharia os objetos de análise, mas sim os aspectos humanos, históricos, ontogenéticos e sócio-históricos que se manifestam nas falas dos operadores. Suas modificações interiores (ontogenéticas, de aquisição de esquemas e de potencialidades de agir) foram o objeto central deste estudo.

Uma vez que a atividade do operador consiste em estar em constante expectação atenta das situações eventuais, buscando enfrentá-las quando da sua ocorrência, a análise em torno dos eventos foi moldada em variáveis de pesquisa que diziam respeito à temporalidade do processo de trabalho. Num processo contínuo, a distância de tempo entre a detecção de um evento e a ação de correção deve ser a menor possível com vistas a manter a estabilidade do processo de produção. Por isso, nos dados a seguir, o tempo gasto nas comunicações de fábrica que antecedem às intervenções é uma variável crucial para a validação das hipóteses ora propostas, estando amplamente contextualizada conforme a descrição das situações avaliadas, conforme atestam as Tabelas 2 e 3.

A história de atuação, objeto de estudo, pôde ser investigada com base no discurso dos operadores, o qual, conforme verificado, sempre remeteu aos eventos e situações concretas da planta. A história de atuação do operador se constituiu, dentre muitas coisas, de vivências de eventos. No discurso dos operadores da IPC, independente de qual fosse o contexto, mostraram-se abundantes as expressões de referência histórica: desde... - antigamente - naquela época - nos tempos do painel lá de baixo - forno satélite - o outro forno - placas antigas - o outro sistema - antes da expansão - depois da troca - a válvula antiga - a bomba que tinha lá - quando a gente trabalhava lá embaixo - tinha vez que - o fluxo era menor - a gente controlava só o forno - não tinha pré-calcinador.

Nas comunicações realizadas com a área de produção, os procedimentos de pesquisa buscaram avaliar a utilização de termos que remetiam à história de incorporação ao processo produtivo, os quais revelaram um saber tácito sobre os equipamentos e suas características e as matérias-primas, ao longo do tempo. Isso ocorria qualquer que fosse o contexto da situação. Daí, não ter havido uma excessiva preocupação em descrever o contexto de cada situação, visto tratar-se de um traço característico de toda e qualquer situação investigada. A prova disso está dada na intensidade com que os operadores, incorporados no contexto da planta (e mais eficientes), se utilizam dos indicadores indiretos. Estes surgem registrados em seu discurso, o qual revela, pelas análises efetuadas segundo rigorosos procedimentos de entrevista, a presença de imagens metafóricas e de esquemas-imagem para ação eficiente sobre o sistema. Aspectos de uma poeira, sua quantidade no interior do forno, distribuição do material sobre a grelha, finura do material, presença de "rio vermelho", etc., surgiram no discurso e não demandaram a descrição detalhada de cada situação: o principal era a fala, qualquer que fosse a situação ou contexto. Esses esquemas-imagem mostraram, em todas as situações estudadas, uma relação direta com os termos de referência histórica e com os indicadores indiretos utilizados pelos operadores. Por isso, não houve a preocupação de relatar, em minúcias situacionais e contextuais, uma única situação específica, dado o caráter genérico e recorrente do fenômeno em estudo.

A análise do discurso buscou averiguar como os indicadores indiretos eram, pelos operadores, correlacionados 
com o comportamento de curvas e parâmetros de telas e como eram utilizados para apreender suas significações no cenário da produção. Essa capacidade de dedução e de inferência revelou-se fruto, conforme mostrou o discurso dos operadores, qualquer que fosse o contexto, de uma vivência histórica do processo de produção, com suas inúmeras situações eventuais.

\subsection{O procedimento de simulação e o estudo do tempo no contexto da pesquisa}

$\mathrm{O}$ procedimento de simulação permitiu demonstrar a maior eficiência de um operador em relação aos demais. Permitiu comprovar a hipótese da incorporação como base da eficiência. Para confrontar as intervenções distintas entre os operadores e demonstrar que não são elaboradas representações distintas, e sim, construídas atuações diferentes com base nas distintas histórias de atuação e de incorporação (embodiment) ao processo de trabalho, foi empregado o procedimento de simulação. Dado o contexto, uma determinada situação real verificada com um operador era oferecida, de maneira simulada, para outro operador e, desta forma, foi possível detectar as distinções de atuação entre eles. Alguns desses resultados constam das tabelas presentes neste texto. Nunca uma atuação foi igual a outra, o que mostra que o mundo da ação não é o mesmo para operadores dotados de diferentes esquemas incorporados de ação.

Os dados foram coletados em situações contextualizadas. Por questão de espaço, todas as condições contextuais e de contorno não puderam ser descritas neste texto, o que não impediu elucidar as causas específicas das ações e comportamentos, eliminando hipóteses conflitantes e outras possíveis causas que poderiam estar interferindo na obtenção e discussão dos resultados sobre a eficiência.

Quando da comparação da ação de dois ou mais operadores distintos, houve o cuidado de selecionar ou simular situações similares de ação, de modo que as condições de contorno fossem as mesmas em cada situação e de modo que as características contextuais fossem as mesmas.

O tempo é uma variável crucial na eficiência do controle de processo contínuo, segundo Bainbridge (1987), e conforme Leplat (1986, 2004). Os processos, devido ao seu caráter dinâmico (PERROW, 1984), requerem uma intervenção rápida, ágil e precisa para que sejam mantidos dentro dos parâmetros de normalidade. Uma vez que a ação no controle de processo na IPC depende das comunicações e diálogos dos operadores com a área de produção, uma variável crucial de estudo para mensurar a eficiência da ação foi o tempo gasto nestes diálogos e nas respectivas intervenções sobre o processo (Tabelas 2 e 3 ), bem como os efeitos dessas intervenções sobre o tempo de permanência do processo num dado estado ou outro.
Nas IPCs, a eficiência está relacionada com a dimensão do tempo associada às intervenções dos operadores. $\mathrm{O}$ conhecimento dos tempos de resposta dos equipamentos a uma dada intervenção, conforme verificado, mostrou se tratar de um componente importante do saber-fazer operatório e da competência incorporada dos operadores numa IPC. Há um certo tempo de latência entre uma intervenção para alteração de alguma variável do processo e sua efetivação. A competência dos operadores envolve uma estimação deste tempo, sob pena da geração de conseqüências indesejáveis para o processo de produção e necessidade de novas intervenções. Isso constituía, conforme demonstrado neste trabalho, uma das dificuldades encontradas pelos operadores em formação e com pouca vivência histórica do processo de produção.

$\mathrm{Na}$ análise do discurso, foi então preciso averiguar os esquemas imagem e as imagens metafóricas associadas aos indicadores indiretos visto que, conforme já descrito na literatura e demonstrado na prática, a utilização destes indicadores indiretos reduz o tempo de tomada de decisão, reduz o tempo de diálogo com os trabalhadores da área e permite uma intervenção que produz efeitos mais regulares sobre o processo. No discurso, verificamos a presença de um saber-fazer que permite passar das instruções aos resultados desejados. Também, na análise das condutas que visavam a antecipação ou diagnóstico e recuperação de um incidente, essa presença ficou evidente.

Um operador menos incorporado ao processo de trabalho, em várias situações, demonstrou encontrar dificuldades para monitorar o sistema. Costumava, conforme registrado em seus diálogos, acessar os supervisores por telefone, com o intuito de obter informações que lhe faltavam ou mesmo entender a significação de determinados eventos. A articulação dos operadores menos incorporados com os demais integrantes do coletivo no tocante a habilidades incorporadas adquiridas é bastante distinta daquela verificada com os operadores peritos. A Tabela 2 revela algumas destas distinções.

A Tabela 1 apresenta os intervalos temporais de realização do estudo.

Tabela 1. Universo empírico da pesquisa.

\begin{tabular}{lccc}
\hline \multicolumn{1}{c}{ Empresa } & $\begin{array}{c}\text { Tipo de } \\
\text { produção }\end{array}$ & $\begin{array}{c}\text { Tempo de } \\
\text { pesquisa/ } \\
\text { meses }\end{array}$ & $\begin{array}{c}\text { Atores } \\
\text { envolvidos }\end{array}$ \\
\hline Siderúrgica 1 & Contínua & 12 & 7 \\
Cimenteira & Contínua & 24 & 9 \\
Siderúrgica 2 & Contínua & 24 & 11 \\
Refinaria & Contínua & 6 & 5 \\
de petróleo & & & \\
\hline
\end{tabular}




\section{Resultados e discussões}

Foram estudados 32 operadores de processo contínuo, em quatro empresas diferentes: Duas siderúrgicas, uma fábrica de cimento e uma refinaria de petróleo. Destes 32, foram selecionados os 17 melhores operadores segundo os seguintes critérios: 1 - Eleição pelos colegas de trabalho ("Quem é o melhor operador aqui, na sua opinião?"); 2 - Segundo os critérios estipulados por Bainbridege (1987): operadores que conseguem resultados esperados por "efeitos diretos" e operadores que necessitam se valer de "aproximações sucessivas/ações contrárias" (BAINBRIDGE, op. cit.). Outros critérios utilizados para seleção dos operadores mais eficientes (segundo os critérios desta mesma autora e de outros):

a) planificam a ação (LEPLAT, 1986) com mais eficiência;

b) controlam o processo com menor variação e com menos oscilações;

c) mantêm o processo por um tempo maior dentro dos níveis esperados de normalidade;

d) tomam decisões mais eficazes;

e) gastam menos tempo nesta tomada de decisão;

f) possuem um vocabulário repleto de imagens metafóricas herdadas do tempo que trabalhavam na área (image-schemata - (JOHNSON, 1987; ROHRER, 2005), as quais permitem uma "intercompreensão" (ZARIFIAN, 2001) mais ágil, rápida e eficiente com os demais atores da produção e um estabelecimento de comunicação que é bem mais eficaz na solução de problemas inesperados, imprevistos, eventos, panes, quebras, desvios de normalidade do processo, desvios e variações na qualidade da matéria-prima, etc.);

g) conseguem retornar o processo aos parâmetros de normalidade com maior rapidez e facilidade que os demais;

h) solucionam problemas com maior rapidez e sem necessidade de recorreções; e

i) Demonstram menos conhecimento teórico, menor atividade de abstração e de raciocínio analítico e estratégias e planificação de ações muito pouco baseadas em regras.

Dos 17 melhores operadores, assim selecionados, que exercem sua atividade conforme as características anteriores, 16 possuem uma história de incorporação à área, ou seja, iniciaram como ajudantes de forneiro, ajudantes de serviços gerais, etc., o que viabilizou a aquisição de esquemas importantes para o controle eficiente do processo de produção contínuo.

Dentre as observações sistemáticas e as entrevistas em autoconfrontação realizadas com os 32 operadores, foram selecionadas, para descrição neste texto, aquelas correspondentes a uma amostra de dois operadores que possuem histórias distintas de "incorporação" nos diferentes cenários da fábrica de cimento. Estas revelaram a existência de formas qualitativamente diferentes de se construir um mesmo problema e intervir no processo produtivo. A aquisição de esquemas incorporados por parte do operador "A", em sua história de contato físico com a produção da fábrica, explicam sua maior eficiência no controle de processo em relação aos demais operadores. Já o operador "B" iniciou sua história no painel de controle, não tendo vivenciado a área de produção, e não possuindo a mesma história de incorporação, embora possua o mesmo tempo de empresa que "A".

O operador "A" demonstra ser mais eficiente conforme os critérios anteriormente citados. Em destaque, os resultados revelaram que ele age pautado por:

a) Regulação em ciclo aberto (BAINBRIDGE, op. cit.);

b) Menor dependência das telas do sistema e do auxílio dos supervisores;

c) Utilização de indicadores indiretos em mais larga escala (que remetem aos image-schemata);

d) Capacidade de antecipar o comportamento da farinha (matéria-prima de fabricação do cimento); e

e) Diálogos mais curtos com o pessoal da área.

Pelas entrevistas, foi reconstituída a história de "A" no processo produtivo. Ele iniciou sua trajetória histórica como ajudante de serviços gerais na área e lá permaneceu, nesta e em outras atividades, por 8 anos. Uma trajetória bastante marcada pela incorporação ao universo físico e material do processo de produção. O operador "B" iniciou sua história diretamente no painel de controle do processo.

Os diálogos entre esses dois operadores com a área demonstram suas distinções de competência incorporada. Esses diálogos, qualitativamente distintos, viabilizam uma tomada de decisão mais ágil, sendo que a ação se dá imediatamente depois deles. As intervenções de "A" são não apenas mais rápidas em comparação com as de "B", mas também menos dependentes da consulta a outras fontes, como informações das telas e apoio de supervisores, além de não provocarem oscilações bruscas nas variáveis de controle do processo produtivo. As Tabelas 2 e 3 contêm alguns dos resultados obtidos, em situações específicas e contextualizadas, que ilustram essas diferenças.

A ligação entre a larga utilização de indicadores indiretos - esquemas-imagem - e os termos que remetem à história do processo foi demonstrada quando da realização da autoconfrontação em situações imediatamente anteriores às ações sobre o processo. São recorrentes, nas verbalizações do operador "A", expressões como: "isso a gente sabe olhar"; "a gente sabe ver"; "a gente faz"; "a gente não vai só na tela...”; "porque a gente já está acos- 
Tabela 2. Dados relativos aos diálogos dos operadores.

\begin{tabular}{|c|c|c|c|c|c|c|c|c|c|c|c|c|c|c|c|}
\hline \multirow[t]{2}{*}{$\begin{array}{c}\text { Número } \\
\text { do } \\
\text { diálogo }\end{array}$} & \multirow[t]{2}{*}{ Situação } & \multicolumn{2}{|c|}{$\begin{array}{l}\text { Duração/ } \\
\text { minutos }\end{array}$} & \multicolumn{2}{|c|}{$\begin{array}{l}\text { Número } \\
\text { de } \\
\text { frases }\end{array}$} & \multicolumn{2}{|c|}{$\begin{array}{c}\text { Número de } \\
\text { termos que } \\
\text { remetem à } \\
\text { história dos } \\
\text { equipamentos }\end{array}$} & \multicolumn{2}{|c|}{$\begin{array}{c}\text { Utilização de } \\
\text { indicadores } \\
\text { indiretos }\end{array}$} & \multicolumn{2}{|c|}{$\begin{array}{c}\text { Consultas } \\
\text { ao } \\
\text { supervisor }\end{array}$} & \multicolumn{2}{|c|}{$\begin{array}{c}\text { Número de } \\
\text { verificações } \\
\text { nas telas do } \\
\text { sistema }\end{array}$} & \multicolumn{2}{|c|}{$\begin{array}{c}\text { Número de } \\
\text { questionamentos } \\
\text { feitos pelo pessoal } \\
\text { da área }\end{array}$} \\
\hline & & A & B & $\mathbf{A}$ & B & $\mathbf{A}$ & B & $\mathbf{A}$ & B & $\mathbf{A}$ & B & $\mathbf{A}$ & B & $\mathbf{A}$ & B \\
\hline 1 & I & 2,0 & 4,0 & 6 & 11 & 1 & 0 & 1 & 0 & 0 & 0 & 1 & 3 & 1 & 3 \\
\hline 2 & II & 0,5 & 1,0 & 2 & 6 & 0 & 0 & 0 & 0 & 0 & 0 & 2 & 2 & 0 & 0 \\
\hline 3 & III & 1,0 & 1,0 & 3 & 4 & 0 & 0 & 1 & 0 & 0 & 0 & 1 & 2 & 1 & 2 \\
\hline 4 & IV & 2,0 & 3,5 & 8 & 14 & 2 & 0 & 3 & 0 & 0 & 0 & 4 & 9 & 1 & 1 \\
\hline 5 & V & 1,25 & 3,0 & 6 & 11 & 1 & 0 & 0 & 0 & 0 & 0 & 1 & 2 & 0 & 1 \\
\hline 6 & VI & 1,5 & 2,0 & 5 & 7 & 1 & 0 & 2 & 1 & 0 & 0 & 1 & 1 & 0 & 0 \\
\hline 7 & VII & 2,0 & 7,0 & 12 & 27 & 3 & 0 & 0 & 0 & 0 & 1 & 1 & 5 & 4 & 6 \\
\hline 8 & VIII & 3,0 & 8,0 & 16 & 41 & 3 & 0 & 0 & 0 & 0 & 1 & 5 & 14 & 2 & 6 \\
\hline 9 & IX & 2,0 & 3,0 & 6 & 8 & 1 & 0 & 2 & 1 & 0 & 1 & 1 & 2 & 4 & 5 \\
\hline
\end{tabular}

Tabela 3. Contextualização das situações descritas na Tabela 2.

\begin{tabular}{cl}
\hline Situação & \multicolumn{1}{c}{ Descrição } \\
\hline I & Aumento da pressão sobre a grelha. Solicitou verificação da área. \\
II & Filtro de transferência do 511: pediu ao forneiro para verificar. \\
III & Solicitou verificação no arrastador, que não liberou. \\
IV & Solicitou a verificação do pré-cal; temperatura estava baixa. \\
V & Solicitou auxílio do forneiro para virar a válvula de clínquer da torre 2 para a torre 1. O clínquer estava travando a válvula \\
& porque o silo estava muito cheio. Nessas situações, faz-se necessário o acompanhamento da área para verificar se a válvula \\
& virou mesmo, para evitar travar a linha. \\
VI & Solicitou os valores de peso-litro para o forneiro. \\
VII & Grelha diminuindo a velocidade. Solicitou verificação do pessoal da mecânica. \\
VIII & Problemas na torre e verificação da tremonha; verificação de válvulas. \\
IX & Problemas no monte de argical.
\end{tabular}

tumado há muito tempo" a "olhar por aî", a "fazer por aî", a "buscar por ali".

Até aqui, não haveria nada de especial nestas distinções se elas não se relacionassem com diferenças nas eficiências de intervenções dos operadores sobre o processo. Se "B" conseguisse ser tão eficiente quanto "A" utilizando-se de indicadores diretos fornecidos pelo sistema (formais), enquanto que "A" utiliza-se mais largamente dos indicadores indiretos, para que deveríamos discutir as distinções entre as estratégias operatórias se ambas garantiriam o controle do processo dentro dos limites de normalidade?

Entretanto, qualitativamente, encontramos distinções significativas nas comunicações, na linguagem e nas intervenções que os operadores " $\mathrm{A}$ " e "B" realizam, as quais refletem nas diferenças de eficiência do controle do processo que os dois conseguem alcançar.

Conforme demonstraram as análises dos dados, referentes a dezenas de situações reais investigadas e a centenas de curvas de oscilações de variáveis de controle de processo armazenadas no sistema, verificamos que "A" é sempre mais rápido e consegue manter o controle do processo sem oscilações bruscas (ao contrário de "B"). Ou, conforme expressões utilizadas por Bainbridge (1987), o operador "A" geralmente obtém um efeito direto enquanto que "B" obtém um efeito por aproximações sucessivas / ações contrárias.

O controle do processo exercido por "A" é mais eficiente do que o exercido por "B" (tomada de decisão mais rápida, intervenções rápidas e seguras que não provocam oscilações bruscas, etc.) graças aos esquemas incorporados e imagens-metáforas do ambiente físico. Estes se materializam nas expressões presentes nos diálogos de "A" com o pessoal da área, em sua linguagem, e nos índices pelos quais ele molda sua ação. São frutos: de sua história de incorporação na fábrica pesquisada e de sua constante integração ao contexto da área. Em sua comunicação com os trabalhadores de campo (área), há expressões que possibilitam um diálogo ágil, em curto espaço de tempo; e, assim, permitem agilizar a tomada de decisão. Essas expressões dizem respeito:

a) às peculiaridades de cada equipamento e distinções em relação aos equipamentos anteriores; 
b) às características singulares de diferentes elementos do processo e suas modificações ao longo do tempo; e

c) a jargões compartilhados socialmente apenas por aqueles que vivenciaram toda a história da fábrica.

Além disso, as ações de "A" se baseiam em percepções de características das matérias primas independentemente dos indicadores formais fornecidos pelo sistema automatizado. As Tabelas 2 e 3 trazem alguns resultados que comprovam as distinções de eficiência entre os operadores "A" e "B".

Alguns exemplos de esquemas-imagem citados e descritos na literatura puderam ser verificados nas situações práticas de ação dos operadores nas IPCs estudadas: container; path; force; part-whole; centre-periphery; link; mass-count; near-far (JOHNSON, 1987; LAKOFF, 1987; TURNER, 1991, 1996; GIBBS; COLSTON, 1995). Vejamos como se materializam na linguagem e na ação dos operadores, em cada situação contextualizada, e como isso demonstra que esses operadores são mais eficientes que os outros:

d) The link image schema (SANTIBÁÑEZ, 2002): situações, respectivamente, de controle da temperatura do forno de cimento e de controle do fechamento do forno na siderúrgica: "A temperatura do forno está ligada na vazão de ar dos ventiladores da grelha" (operador da cimenteira). O operador em questão se mostrou mais eficiente na manutenção da estabilidade da temperatura do forno. "A fumaça preta indica que o forno não foi fechado direito. (...) Eu amarro a fumaça no problema do forno. Eu sei que uma coisa vem junto da outra" (operador da siderúrgica). Este operador se mostrou mais eficiente na detecção de problemas de fechamento do forno e na ação de corrigir o problema.

e) The part-whole image schema (SANTIBÁÑEZ, 2002): situações de detecção de desgaste das placas da grelha na fábrica de cimento, e de problemas com os eletrodos de grafite na siderúrgica, respectivamente. "A grelha é feita de placas e essas placas desgastam assim ... umas gastam mais que as outras, e aí tem que trocar" (operador da cimenteira). Este operador se mostrou mais eficiente, nesta situação, em detectar e comunicar a necessidade de troca das placas da grelha. "O dangueiro tem que deixar o pé do eletrodo sempre com carga, como se a carga fosse uma parte do eletrodo" (operador da siderúrgica). Este operador se mostrou mais eficiente, nesta situação, em detectar ausência de carga no eletrodo e, também, em comunicar o problema. "Um eletrodo desses é feito de blocos de grafite que desgastam na reação" (operador da siderúrgica). Este operador se mostrou mais eficiente, nesta situação, em detectar e comunicar o desgaste do eletrodo de grafite. f) Thecentre-peripheryimageschema(SANTIBÁÑEZ, 2002): situação de controle e comunicação sobre a quantidade de material no eletrodo do forno siderúrgico. "O dangueiro tem que ficar esperto porque o material vai se esparramando em volta do eletrodo, e ele tem que ir empurrando ele pro meio novamente. Eu vejo isso também aqui na tela, mas principalmente na fumaça" (operador de siderúrgica). Este operador se mostrou, nesta situação, mais eficiente no controle e na comunicação sobre o material ao redor do eletrodo.

g) The mass-count image schema (SANTIBÁÑEZ, 2002): situações de controle da velocidade da grelha na fábrica de cimento, e do conteúdo de material fundido na siderúrgica, respectivamente. "À medida que o material vai caindo na grelha, ela vai enchendo e o material vai pesando mais a grelha e ela vai ficando mais lenta" (operador da cimenteira). Este operador, nesta situação, se mostrou mais eficiente no controle da velocidade da grelha, permitindo uma maior homogeneidade do material sobre ela. "O lingote vai enchendo e a panela vai ficando mais leve. $\mathrm{O}$ operador da ponte tem que ser bom no controle da panela" (operador da siderúrgica). Este operador se mostrou, nesta situação, mais eficiente na comunicação com o operador da ponte sobre o conteúdo de material fundido na panela e no lingote.

h) The stand-verticality-horizontality image schema (LEMMENS, 2004): situações de controle do material sobre a grelha (fábrica de cimento) e do volume de material dentro do lingote (siderúrgica), respectivamente. "O material vai caindo na grelha e vai formando um monte que sobe, cresce para cima... É o boneco de neve. Ele avacalha a temperatura do sistema" (operador da cimenteira). Este operador se mostrou, nesta situação, mais eficiente no controle do material sobre a grelha. "O material fundido vai rolando e forma uma lâmina fina em cima do lingote, e vai enchendo e subindo até a borda, mas sem transbordar" (operador da siderúrgica). Este operador se mostrou, nesta situação, mais eficiente na comunicação com o operador de ponte e com o lingoteiro.

i) The near-far image schema (LEMMENS, 2004): situação de controle do material sobre a grelha. "À medida que ela balança, ela vai levando o material para longe da boca do forno" (operador da cimenteira). Este operador se mostrou, nesta situação, mais eficiente no controle da velocidade da grelha com o objetivo de homogeneizar o material sobre ela.

j) The full-empty image schema (LEMMENS, 2004): situações de controle do volume de material nos 
lingotes (siderúrgica) e de controle da velocidade da grelha (fábrica de cimento), respectivamente. "A panela vai esvaziando e o lingote vai enchendo" (operador de siderúrgica). Este operador se mostrou, nesta situação, mais eficiente na comunicação com o lingoteiro e com o operador de ponte para controlar o processo de enchimento dos lingotes. "Se a grelha vai enchendo, tem que fazer ela esvaziar; e a gente vai movendo o material pra frente para ela esvaziar senão atrapalha a temperatura do forno" (operador da cimenteira). Este operador se mostrou, nesta situação, mais eficiente no controle da velocidade da grelha com o objetivo de homogeneizar o material sobre ela.

k) The movement, activity and functionality image schemata (LEMMENS, 2004): situação de antecipação dos estados futuros do processo com vistas a evitar situações eventuais. "Eu vou entrando pra dentro das telas do sistema e tenho que ajustar um parâmetro já voltando pra trás e indo corrigindo as mudanças que ele mesmo já vai causando nos outros" (operador da siderúrgica). "Eu levanto a temperatura baixando a vazão de ar e ficando de olho no balanço da grelha, que não pode acumular material senão sobe a temperatura de novo..." (operador da cimenteira). Em ambas as situações, estes operadores se mostram mais eficientes em antecipar os estados futuros do processo e em agir de forma a evitar situações eventuais.

1) The balance image schema (LEMMENS, 2004): situação de antecipação dos estados futuros do processo com vistas a evitar situações eventuais. "O forno tem que ficar equilibrado e para equilibrá-lo tem que controlar o recuperador; quando o recuperador oscila, ele faz alterar a temperatura e a pressão do sistema todo" (operador da cimenteira). Este operador se mostrou, nesta situação, mais eficiente em antecipar os estados futuros do processo e em agir de forma a evitar situações eventuais.

Os registros de discursos dos operadores, analisados de acordo com o contexto das situações de entrevista, mostram que a compreensão conceitual ou a abstração do operador de processo contínuo ocorre como uma metáfora da compreensão do próprio movimento deste no trabalho. Os conceitos e proposições na mente são como que metáforas de movimentos e atos provenientes do corpo que atua e se incorpora (e que atuou e se incorporou, historicamente) no processo de trabalho.

Esta espécie de sistema metafórico, muito bem explicado por Johnson \& Rohrer (2006) e por Johnson (1987), projeta-se na linguagem e na ação, enquanto meios de raciocinar, de planificar a ação e de gerar compreensão para inúmeras situações no trabalho, conforme demonstrado pelos resultados acima. A compreensão de uma proposição envolve estar situado, contextualmente atuante (incorporado, en-agido) no contexto físico do processo produtivo.

\section{Considerações finais}

Este texto verificou, pela linguagem dos operadores, que os image-schemas, na atividade de controle de processo contínuo, funcionam como categorias conceituais, ou conceitos pragmáticos para a ação em um modelo operativo, que permitem articular as propriedades da ação - invariância e adaptabilidade - de modo a torná-la eficaz (PASTRÉ, 2005). São categorias metafóricas férteis em tornar a ação eficaz. Verificou-se que os operadores mais eficientes compreendem o processo de produção por meio dessas metáforas em sua experiência diária. Os operadores mais eficientes agem incorporados no contexto das situações materiais da produção, por intermédio de suas funções sensoriais, perceptivas e sensório-motoras situadas no corpo. "Nós, humanos, pensamos com atos e nós agimos como modo (meio) de construir pensamento ("representação") - cognição é ação" (JOHNSON; ROHRER, 2006).

Há uma base vivencial, experiencial, corporificada das componentes abstratas da ação de controle de processo contínuo. Há, nelas, uma estrutura interna ontologicamente prioritária, material, que se estende como estrutura do entendimento e da compreensão das situações oferecidas pelo real do trabalho nas IPCs. Os embodied-schemata e os image-schemata exercem um papel fundamental na significação dos estados do processo e nos raciocínios hipotético e dedutivo para ação de controle da produção. Conforme demonstram os resultados, a base experiencial, incorporada e situada, arraigada na experiência corporal, permite a componente cognitiva da atividade de trabalho funcionar de modo eficiente no controle do processo.

Ora, mas no lugar da representação, que sob o ponto de vista do objetivismo é puramente abstrata e descolada das funções corporais (sensório-motoras, perceptivas), como no clássico dualismo mente-corpo de Descartes, encontram-se, para longe deste realismo representativo cartesiano, as construções incorporadas ou esquemas incorporados gerados pela história de inserção no dado processo de trabalho, cognitivo e, ao mesmo tempo, corporal. Estas construções emergem, na atividade mental, a partir do corpo que age, atua e se insere no contexto da planta, nas situações da área de produção. 


\title{
The embodied mind in the control of a continuous process: action, cognition, and communication in work activities
}

\begin{abstract}
The main objective of this paper is to analyze, in detail, the embodied cognition as an incorporated action in a continuous process control. The method of research adopted was the ergonomic work analysis. The results show that the operators do not represent an external world, but instead they act think and act independently. The key point in this study is that lacking an internal representation the workers (operators) engage in Sensory-Motor Activities in work practical activities in response to environmental changes. There is no rupture among the perceiving, feeling, and thinking experiences. This study aims at investigating how socio and cultural processes are demanded to develop imageschemata and embodied-schemata, which can lead to abstract thinking using perception skills and motor response. This work suggests that linguistic expressions and higher cognitive processes evidence recurrent body experience dynamic patterns denominated image-schemata. It was founded that these patterns can be extended to non-tactile, non-physical, and non-visual experience structures.
\end{abstract}

Keywords: Ergonomics. Activity. Process control. Embodied mind.

\section{Referências bibliográficas}

BAINBRIDGE, L. Ironies of automation. In: RASMUSSEN, J.; DUNKAN, K.; LEPLAT, J. New technology and human error. New York: John Wiley \& Sons Ltd., 1987.

BECKER, H. S. Métodos de Pesquisa em Ciências Sociais. São Paulo: Hucitec, 1997.

BERTHOZ, A. Le sens du mouvement. Paris: Odile Jacob, 1997.

ENRIQUEZ, E. La Psychosociologie au carrefour. Revue Internationale de Psychosociologie, v. 1, n. 1, p.1-12, ago. 1995.

GIBBS, R. W.; COLSTON, H. L. The cognitive psychological reality of image schemas and their transformations. Cognitive linguistics, v. 6, n.1, p. 347-378, nov. 1995.

GUÉRIN, F. et al. Compreender o trabalho para transformá-lo: a prática da Ergonomia. São Paulo: Edgard Blücher, 2002.

JACKENDOFF, R. Consciousness and the Computational Mind. Cambridge: MIT Press, 1987.

JOHNSON, M. The body in the mind: the bodily basis of imagination, reason and meaning. Chicago: University of Chicago Press, 1987.

JOHNSON, M.; ROHRER, T. We are live creatures: Embodiment, American Pragmatism, and the Cognitive Organism. In: ZLATEV, J. et al. (Eds.). Body, language and mind. v. 1. Berlim: Mouton de Gruyter, 2006.

LAKOFF, G.; JOHNSON, M. Metaphors we live by. Chicago: University of Chicago Press, 1980.

LAKOFF, G. Women, fire and dangerous things. Chicago: University of Chicago Press, 1987.

LAVE, J. The practice of learning. In: CHAIKLIN, S.; LAVE, J. (Eds). Understanding practice: perspectives on activity and context. New York: Cambridge University Press, 1996.

LEMMENS, M. Metaphor, image schema and grammaticalisation: a cognitive lexical-semantic study. Journée d etudes grammar and figures of speech, v.3, n.4, p.24-46, Fev. 2004.
LEPLAT, J. L'analyse du travail en psychologie ergonomique. Paris: Octarès Éditions, 1986.

LEPLAT, J. Aspectos da complexidade em ergonomia. In: DANIELLOU, F. A Ergonomia em busca de seus princípios. São Paulo: Edgard Blücher, 2004.

PASTRÉ, P. Genèse et identité. In: In: RABARDEL, P.; PASTRÉ, $P$. Modèles du sujet pour la conception; dialectiques activités développement. Paris: Octarès Éditions, 2005.

PERROW, C. Normal Acidents. New York: Basic Books, 1984.

PESCHL, M. Understanding representation in the cognitive science. New York: Kluwer Academic, 2000.

RABARDEL, P. Instrument subjectif et développement du pouvoir d'agir. In: RABARDEL, P.; PASTRÉ, P. Modèles du sujet pour la conception; dialectiques activités développement. Paris: Octarès Éditions, 2005

ROHRER, T. Image Schemata in the Brain. In BEATE, H. \& GRADY, J. (Eds). From Perception to Meaning: Image Schemas in Cognitive Linguistics. Berlim: Mouton de Gruyter, 2005, p. 165-196.

ROHRER, T. The body in space: dimensions of embodiment. In: ZLATEV, J. et al. (Eds.). Body, language and mind. Berlim: Mouton de Gruyter, 2006.

SANTIBÁÑEZ, F. The object image-schema and other dependent schemas. Atlantis, v. 24, n. 2, p.16-49, dez. 2002.

TURNER, M. Reading Mings: the study of english in the age of cognitive science. Princeton, NJ: Princeton University Press.

VYGOTSKY, L. S. Teoria e método em psicologia. São Paulo: Martins Fontes, 1996.

WISNER, A. Por dentro do trabalho: ergonomia - método e técnica. São Paulo: FTD-Oboré, 1987.

WISNER, A. Situated Cognition and Action: Implications for Ergonomic Work Analysis and Anthropotechnology. Paris: Laboratoire d'Ergonomie, CNAM, 1994.

ZARIFIAN, P. Objectiv Compétence. Paris: Liasons, 1999 


\section{Sobre os autores}

\section{Gilbert Cardoso Bouyer}

Universidade Federal de Ouro Preto - UFOP, Campus João Monlevade,

Rua 37, n. 115, Bairro Loanda, CEP 35930-970, João Monlevade, MG, Brasil,

e-mail: gilbertcb@uol.com.br

Agradecimentos: aos professores que contribuíram com suas críticas e sugestões para a realização deste trabalho: Mário Sérgio Salerno, Seiji Uchida, Ricardo Musse, Fausto Leopoldo Máscia e Laerte Idal Sznelwar.

Recebido em 18/12/2008

Aceito em 14/9/2008 